\title{
Postural Analysis on Manual Pine Resin Collecting Work: Lifting Index and L5/S1 Compression-Shear Forces
}

\author{
Efi Yuliati Yovi", Nasruli Awaliyah \\ Department of Forest Management, Faculty of Forestry and Environment, IPB University. Jl. Raya Dramaga, Bogor \\ 16680, West Java, Indonesia \\ ${ }^{*}$ Corresponding Author. E-mail address: eyyovi@apps.ipb.ac.id
}

ARTICLE HISTORY:

Received: 12 April 2021

Peer review completed: 18 April 2021

Received in revised form: 8 August 2021

Accepted: 1 September 2021

KEYWORDS:

Biomechanics

Ergonomics

Forestry work

Manual lifting

Oleoresin harvesting

(C) 2021 The Author(s). Published by Department of Forestry, Faculty of Agriculture, University of Lampung in collaboration with Indonesia Network for Agroforestry Education (INAFE) This is an open access article under the CC BY-NC license:

https://creativecommons.org/licenses/by$\mathrm{nc} / 4.0 \%$.

\begin{abstract}
Even though pine oleoresin harvesting is labor-intensive forestry work involving manual material handling (especially lifting) and is massively carried out in Indonesia, there is a lack of ergonomics studies on manual pine oleoresin harvesting. This study focused on lifting-related postures in pine oleoresin harvesting. A Three Dimension Static Strength Prediction Program Version 7.1.0 was used to identify the injury risk on the lower back (lumbosacral joint, L5/S1) using biomechanical criteria (compression and shear forces) at extreme postures. Recommended Weight Limit (RWL) and Lifting Index (LI) were calculated for a comprehensive analysis. The exceeding compression and shear forces indicated that the L5/S1 injury risk on oleoresin collecting work (part of oleoresin harvesting) is high. The psychophysical analysis confirmed the findings, as several main postures in this work were categorized as intense manual lifting due to the excessive score of LI. A significant reduction in the L5/S1 compression and shear forces were shown at a simulation using a proposed load threshold (using the calculated RWL).
\end{abstract}

\section{Introduction}

Many countries still maintain manual or motor-manual methods for harvesting pine oleoresin (Cunningham 2012), tree-felling, and log-hauling (Yovi and Yamada 2019; Jourgholami et al. 2020). These labor-intensive forestry works are characterized by the intense use of human power to move or support objects, such as lifting, lowering, pushing, pulling, carrying, holding, or restraining. These activities, known as manual material handling $(\mathrm{MMH})$, expose workers to great risk factors that lead to costly occupational health disorders (Banks and Aghazadeh 2009; Kuijer et al. 2011; Hasegawa et al. 2018). In addition to a high physical workload, MMH in forestry work often exposes workers to an exceeding natural range of motion (Openshaw and Taylor 2006). This exceeding range of motion, which has been proven to cause musculoskeletal disorders (MSDs), may trigger excessive pressure on the lower back intervertebral disk (especially in the lumbosacral joint, known as L5/S1), resulting in lower back injuries (Kumar 2001; Sakka et al. 2015).

Globally, lower back pain has remained one of the top two contributors to disability causes for over two decades (Vos et al. 2010). The lower back injury is associated with the worker's lower quality of life (Husky et al. 2018). It is a disadvantage financially, causing productivity loss (Dutmer et al. 2019) and social costs (Fujii and Matsudaira 2013). There is currently no data 
regarding back pain costs in Indonesia. However, in the Netherlands, pain consumes $1-2 \%$ of its gross national product (Lambeek et al. 2011).

Even though pine forests in Indonesia reach 124,290 ha (BPS 2017), indicating a high number of workers involved in forest management, only a few postural studies focus on manual pine oleoresin harvesting. The studies that have been carried out were the aspects of physical workload (Yovi et al. 2005) and score-based static postural analysis by using Rapid Entire Body Assessment (REBA) and Rapid Upper Limb Assessment (RULA) (Yovi and Fauzi 2021). The scoring-based instruments have been widely used in various postural studies (Dempsey et al. 2005) and are considered effective in revealing postural stress (Kee and Karwowski 2007). The study by Yovi and Fauzi (2021) indicates that oleoresin collecting workers are imposed with lower back pain. However, the total compression and shear forces received at L5/S1 associated with lower back pain (LBP) have not been investigated. Therefore, a postural study on manual oleoresin collecting with a biomechanical approach is necessary.

This study aims to calculate the compression and shear force on the L5/S1 and propose alternative postures for oleoresin collecting work for better safety and health protection. This study will complement the existing ergonomics risk analyses and can be used to determine the proper strategy for reducing the MSDs risk in oleoresin collecting work activities.

\section{Materials and Methods}

This research was conducted in a pine plantation in West Java, Indonesia, from February to March 2020. We observed the actual postures of 30 respondents during a preliminary study, aiming to identify a common posture in oleoresin collecting activity. Out of the 30 observed workers, three representative workers were recruited for detailed postural analysis. The regular postures while performing the actual work (30 cycles per worker) were recorded using two video cameras placed at an angle perpendicular to the sagittal plane (left and right) around the body's axis. Depending on the possible recording position, a video camera was placed upright in the coronal plane to provide visuals from the front or backside. This biomechanics analysis was carried out only on the maximum-load lifting postures identified using a time and motion study concept. During observations, collecting work was carried out for around two hours. The maximum load in this study was $34 \mathrm{~kg}$, based on a full oleoresin bucket's weight. The biomechanics analysis was carried out on both current and proposed postures. A graphical representation of this research flowchart is shown in Fig. 1.

\subsection{L5/S1 Compression and Shear Forces Analysis}

Information on biomechanical features is necessary to improve postures to the most effective and safest patterns (Knudson 2007). This study's biomechanics modeling and analysis were carried out using the 3 Dimension Static Strength Prediction Program Version 7.1.0 (3DSSPP Version 7.1.0) developed by the University of Michigan. The mathematical models for this software follow the principles described by Chaffin et al. (2006). The 3DSSPP sets the Back Compression Design Limit (also known as Action Limit/AL) under the criteria used to develop the revised 1991 lifting equation at 3,400 N (Waters et al. 1993). The Back Compression Upper Limit corresponds to the Maximum Permissible Limit (MPL) set at 6,400 N (NIOSH 1981). 


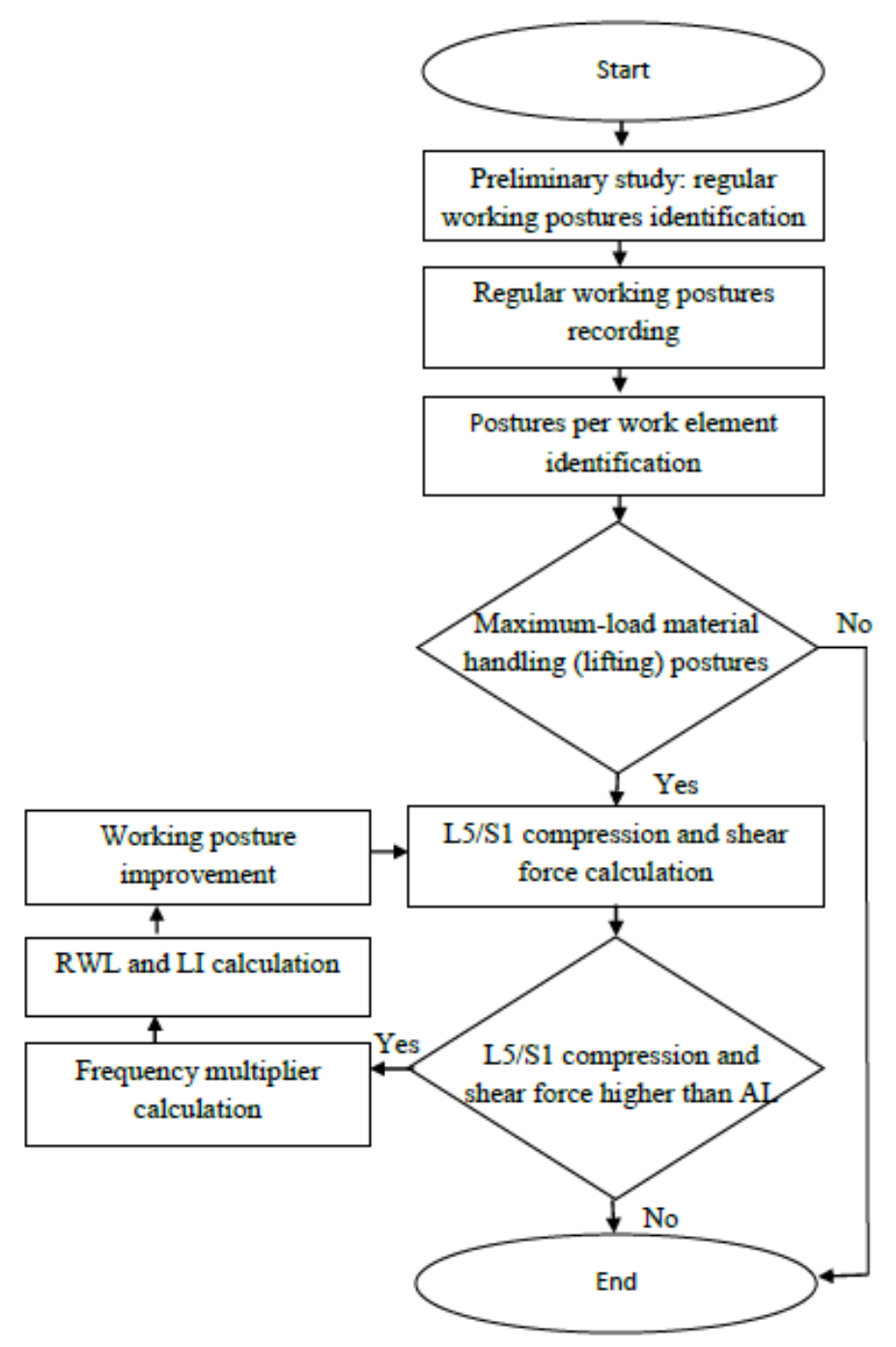

Fig. 1. The flowchart of the biomechanics analysis on pine oleoresin collecting work.

A load of L5/S1 greater than 3,400 N potentially increases the risk of injury by three times more than a load below 3,400 N (Chaffin and Anderson 1991). In comparison, a load above 6,400 $\mathrm{N}$ is hazardous and can provide an injury risk of 10 times more than a load below 3,400 N (Nelson et al. 1995). In this study, we set $500 \mathrm{~N}$ as a shear force safe limit. This limit follows the recommendation from the ergonomic research group of the University of Waterloo (McGill et al. 1998). The study's right and left-hand load ratios were determined through subjective estimation during field observation and laboratory reconstructions.

\subsection{Lifting Index (LI) Calculation}

The Recommended Weight Limit (RWL) value is used to determine LI, a psychophysical reference for estimating a worker's physical stress caused by manual handling. A time study analysis was carried out on 90 cycles of oleoresin collecting work to calculate the frequency multiplier (FM). The following is a formula originated by NIOSH (1994) to calculate the RWL:

$$
R W L=(L C)(H M)(V M)(D M)(A M)(F M)(C M)
$$


where RWL is Recommended Weight Limit ( $\mathrm{kg}), \mathrm{LC}$ is the load constant (23 kg), HM is the horizontal multiplier $(25 / \mathrm{H}), \mathrm{VM}$ is the vertical multiplier $(1-(0.003|\mathrm{~V}-75|))$, DM is the distance multiplier $(0.82+(4.5 / \mathrm{D})), \mathrm{AM}$ is the asymmetric multiplier $(1-(0.0032 \mathrm{~A}))$, FM is the frequency multiplier (the average number of lifts/lowering tasks per minute), and CM is the coupling multiplier. $\mathrm{H}(\mathrm{cm})$ in $\mathrm{HM}$ is the horizontal distance between the point projected on the floor directly below the mid-point of the hands grasping the load center and the mid-point of a line between the inside ankle bones. V $(\mathrm{cm})$ in VM is the vertical location of the hands, which is the vertical location of the hands above the floor at the origin. D $(\mathrm{cm})$ in DM is vertical transfer, determined by subtracting the $\mathrm{V}(\mathrm{cm})$ at the start of the lift from the $\mathrm{V}(\mathrm{cm})$ at the end of the lift. A in AM is the asymmetric angle $\left({ }^{\circ}\right)$, which is the degree to which the body is required to twist or turn during the lifting task or angular displacement from the load measured from the sagittal plane.

The $\mathrm{LI} \leq 1.0$ indicates a little risk to health workers, while $1<\mathrm{LI}<2$ indicates that lifting is safe but can be physically stressful. $3<$ LI means a significant level of physical stress and health concerns. The following is a formula to calculate the LI (NIOSH 1994):

$$
L I=\frac{L}{R W L}
$$

where LI is the Lifting Index, L is the weight of the lifted object $(\mathrm{kg})$, and RWL is the Recommended Weight Limit (kg).

\section{Results and Discussion}

\subsection{Results}

\subsubsection{L5/S1 compression and shear forces}

The oleoresin collecting work is a part of the oleoresin harvesting activity. In this work, the pine oleoresin is collected from each pot installed on each tapping surface. A complete collecting work is split up into four value-added elements:

- Carrying a lugging bucket when walking from one to another tree (work element, hereafter denoted as WE; WE1),

- Pouring the accumulated oleoresin in the pots into the lugging bucket (maximum weight is 34 $\mathrm{kg}$ ) (WE2),

- Shouldered the full-load lugging bucket when walking to the transitory storage point (WE3),

- Pouring the oleoresin from the lugging bucket into the plastic drum at the transitory storage point (WE4).

Lift postures in those four elements can vary among workers due to their self-selected lift styles.

A preliminary analysis showed six postures (hereafter denoted as P; P1 in WE1; P2, P3, and P4 in WE3; P5 and P6 in WE4) were carried out as maximum-load lifting. These six selected critical postures were modeled using the 3DSSPP software (front view from $+Y$ axis, side view from -X-axis, and hominoid view) to calculate the L5/S1 lower back compression and shear forces at each posture. The anthropometric data used in this study was taken from the average height and bodyweight of the 30 respondents: $162.8 \mathrm{~cm}$ in height and $57.4 \mathrm{~kg}$ in body weight. The biomechanics analysis showed that the current oleoresin collecting work imposed workers with 1,614-3,945 $\mathrm{N}$ of compression force and 406-648 $\mathrm{N}$ of shear force (Fig. 2). 


\begin{tabular}{|c|c|c|c|c|c|}
\hline \multicolumn{2}{|c|}{$\begin{array}{c}\text { Posture (based on } 162.8 \\
\text { cm of height, } 57.4 \mathrm{~kg} \text { of } \\
\text { body weight) }\end{array}$} & $\begin{array}{l}\text { Front view } \\
\text { from the } \\
+Y \text { axis }\end{array}$ & $\begin{array}{l}\text { Side view from } \\
\text { the }-X \text { axis }\end{array}$ & Hominoid-view & $\begin{array}{l}\text { Sagittal plane lower } \\
\text { back analysis report }\end{array}$ \\
\hline \multicolumn{6}{|c|}{ WE1: carrying a lugging bucket while walk from one tree to another tree } \\
\hline $\mathrm{P} 1$ & & & 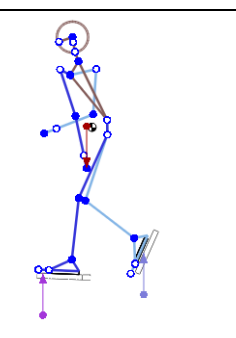 & & $\begin{array}{l}\text { CF: } 1,614 \pm 93 \mathrm{~N} \\
\text { SF: } 406 \mathrm{~N} \\
\text { Lifting frequency: } 5 \\
\text { lifts/minute } \\
\text { Load ratio (right/left): } \\
10 / 0 \\
\text { Balance: acceptable }\end{array}$ \\
\hline \multicolumn{6}{|c|}{ WE3: shouldered the full lugging bucket when walking to the oleoresin collection point (drum) } \\
\hline P2 & 8 & . & & & $\begin{array}{l}\text { CF: } 3,792 \pm 278 \mathrm{~N} \\
\text { SF: } 572 \mathrm{~N} \\
\text { Lifting frequency: } 0.2 \\
\text { lifts/minute } \\
\text { Load ratio (right/left): } \\
8 / 2 \\
\text { Balance: critical }\end{array}$ \\
\hline P3 & E. & & . & & $\begin{array}{l}\text { CF: } 3,945 \pm 213 \mathrm{~N} \\
\text { SF: } 424 \mathrm{~N} \\
\text { Lifting frequency: } 0.2 \\
\text { lifts/minute } \\
\text { Load ratio (right/left): } \\
8 / 2 \\
\text { Balance: Acceptable }\end{array}$ \\
\hline P4 & & & & & $\begin{array}{l}\text { CF: } 1,883 \pm 101 \mathrm{~N} \\
\text { SF: } 600 \mathrm{~N} \\
\text { Lifting frequency: } 0.2 \\
\text { lifts/minute } \\
\text { Load ratio (right/left): } \\
10 / 0 \\
\text { Balance: Acceptable }\end{array}$ \\
\hline \multicolumn{6}{|c|}{ WE4: pour the oleoresin from the lugging bucket into the plastic drum } \\
\hline P5 & $\frac{4 x^{2}}{1 x^{2}}$ & $\int_{0}^{3}$ & 8 & & $\begin{array}{l}\text { CF: } 2,060 \pm 133 \mathrm{~N} \\
\text { SF: } 414 \mathrm{~N} \\
\text { Lifting frequency: } 0.2 \\
\text { lifts/minute } \\
\text { Load ratio (right/left): } \\
\text { 2/8 } \\
\text { Balance: unacceptable }\end{array}$ \\
\hline
\end{tabular}




\begin{tabular}{|c|c|c|c|c|c|}
\hline \multicolumn{2}{|c|}{$\begin{array}{c}\text { Posture (based on } 162.8 \\
\text { cm of height, } 57.4 \mathrm{~kg} \text { of } \\
\text { body weight) }\end{array}$} & $\begin{array}{l}\text { Front view } \\
\text { from the } \\
+Y \text { axis }\end{array}$ & $\begin{array}{l}\text { Side view from } \\
\text { the }-X \text { axis }\end{array}$ & Hominoid-view & $\begin{array}{l}\text { Sagittal plane lower } \\
\text { back analysis report }\end{array}$ \\
\hline P6 & 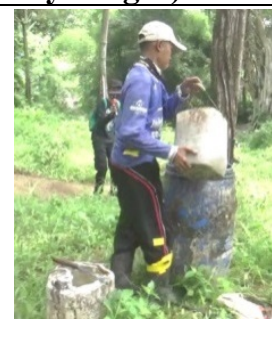 & 8 & & & $\begin{array}{l}\text { CF : } 1,716 \pm 120 \mathrm{~N} \\
\text { SF: } 418 \mathrm{~N} \\
\text { Lifting frequency: } 0.2 \\
\text { lifts/minute } \\
\text { Load ratio (right/left): } \\
6 / 4 \\
\text { Balance: unacceptable }\end{array}$ \\
\hline
\end{tabular}

Note: CF is compression force, SF is shear force. CF and SF were calculated based on $34 \mathrm{~kg}$ weight load.

Fig. 2. The side and hominoid views model on the six selected postures.

\subsubsection{Lifting Index}

LI was calculated for WE1, WE3, and WE4. The H, V, and D values used for the RWL calculations were the most extreme values measured from the 90 cycles of observed work. The actual lifting (and lowering) frequency was nine times/minute, resulting in the FM being 0.26. For two hours of work duration and V $<75 \mathrm{~cm}$, the coupling type in WE1 was categorized as "fair", with a CM score of 0.95 . Therefore, the RWL and LI values for lifting tasks in WE1 were set at $3.5 \mathrm{~kg}$ and 9.7. At WE3, the asymmetry angle was $45^{\circ}$. According to NIOSH (1994), lifting tasks with a frequency of less than one lift every 5 minutes should be set at $0.2 \mathrm{lifts} /$ minute. Thus, the FM for WE3 was equal to 0.95 . The CM for this task was similar to WE1. Therefore, the RWL and LI values for lifting tasks in WE3 were set at $9.8 \mathrm{~kg}$ and 3.5. In WE4, the lifting task was carried out when the workers poured oleoresin into a plastic drum (200-litre capacity, height 93 $\mathrm{cm}$, diameter $58 \mathrm{~cm}$ ). Lifting in this posture was carried out for 54 seconds every 2,544 seconds (on average), resulting in $0.2 \mathrm{lifts} /$ minute of lifting frequency. The coupling type for this task was categorized as fair, and with $\mathrm{V}<75 \mathrm{~cm}$, the $\mathrm{CM}$ was considered 1.00 . Therefore, for a $34 \mathrm{~kg}$ load, the RWL and LI for this work element were $10.8 \mathrm{~kg}$ and 3.1. All variables for the RWL and LI calculation are presented in Table 1.

Table 1. The NIOSH lifting variables on lifting tasks in the WE1, WE3, and WE4

\begin{tabular}{ccccccc}
\hline $\begin{array}{c}\text { Work element } \\
\text { with lifting task }\end{array}$ & \multicolumn{7}{c}{ NIOSH Lifting Variable } \\
\hline \multirow{4}{*}{ Work element 1 } & $\mathrm{H}(\mathrm{cm})$ & $\mathrm{V}(\mathrm{cm})$ & $\mathrm{D}(\mathrm{cm})$ & $\mathrm{A}\left(^{\circ}\right)$ & $\mathrm{HM}$ & $\mathrm{VM}$ \\
\cline { 2 - 7 } & 32 & 35 & 30 & 22.5 & 0.78 & 0.88 \\
\cline { 2 - 7 } & $\mathrm{DM}$ & $\mathrm{AM}$ & $\mathrm{FM}$ & $\mathrm{CM}$ & $\mathrm{RWL}$ & $\mathrm{LI}$ \\
\cline { 2 - 7 } & 0.97 & 0.928 & 0.26 & 0.95 & 3.5 & 9.7 \\
\hline Work element 3 & $\mathrm{H}(\mathrm{cm})$ & $\mathrm{V}(\mathrm{cm})$ & $\mathrm{D}(\mathrm{cm})$ & $\mathrm{A}\left(^{\circ}\right)$ & $\mathrm{HM}$ & $\mathrm{VM}$ \\
\cline { 2 - 7 } & 30 & 0 & 133 & 45.0 & 0.83 & 0.775 \\
\cline { 2 - 7 } & $\mathrm{DM}$ & $\mathrm{AM}$ & $\mathrm{FM}$ & $\mathrm{CM}$ & $\mathrm{RWL}$ & $\mathrm{LI}$ \\
\hline Work element 4 & 0.85 & 0.856 & 0.95 & 0.95 & 9.8 & 3.5 \\
& $\mathrm{H}(\mathrm{cm})$ & $\mathrm{V}(\mathrm{cm})$ & $\mathrm{D}(\mathrm{cm})$ & $\mathrm{A}\left(^{\circ}\right)$ & $\mathrm{HM}$ & $\mathrm{VM}$ \\
\cline { 2 - 7 } & 30 & 0 & 93 & 22.5 & 0.83 & 0.775 \\
\cline { 2 - 7 } & $\mathrm{DM}$ & $\mathrm{AM}$ & $\mathrm{FM}$ & $\mathrm{CM}$ & $\mathrm{RWL}$ & $\mathrm{LI}$ \\
\cline { 2 - 7 } & 0.87 & 0.928 & 0.95 & 1.00 & 10.8 & 3.1 \\
\hline
\end{tabular}

Notes: $\mathrm{H}$ is horizontal distance, $\mathrm{V}$ is vertical location, $\mathrm{D}$ is vertical transfer, $\mathrm{A}$ is asymmetric angle, $\mathrm{HM}$ is horizontal multiplier, VM is vertical multiplier, DM is distance multiplier, AM is asymmetric multiplier, FM is frequency multiplier, CM is coupling multiplier, RWL is Recommended Weight Limit, LI is Lifting Index, all values were calculated based on $162.8 \mathrm{~cm}$ height and $57.4 \mathrm{~kg}$ weight of biotype. 


\subsubsection{Simulation of the alternative collecting process}

Calculation results on CF, SF, and LI (Fig. 2, Table 1) showed that although not all work postures caused a compression and shear force that exceeded their AL values, the LI values in all postures far exceeded the safe limit (Table 2). This condition reflected the evidence of the workers' physical stress when performing oleoresin collecting activities at a $34 \mathrm{~kg}$ bucket load. Therefore, it is necessary to improve work techniques for a safer physical load. The alternative work process with a lighter load, $3.5 \mathrm{~kg}$ for WE1 and $10.5 \mathrm{~kg}$ for WE3 and WE4, showed a lower compression and shear force than the AL (Table 3).

Table 2. The tabulation of CF, SF, and LI compared to the Action Limit in the current work technique

\begin{tabular}{ccccc}
\hline Posture* $^{*}$ & Max-load (kg) & LI & CF (N) & SF (N) \\
\hline WE1P1 & 34 & 9.7 & $1614 \pm 93 \mathrm{~N}$ & $406 \mathrm{~N}$ \\
\hline WE3P2 & 34 & & $3792 \pm 278 \mathrm{~N}$ & $572 \mathrm{~N}$ \\
\hline WE3P3 & 34 & 3.5 & $3945 \pm 213 \mathrm{~N}$ & $424 \mathrm{~N}$ \\
\cline { 1 - 3 } WE3P4 & 34 & & $1883 \pm 101 \mathrm{~N}$ & $600 \mathrm{~N}$ \\
\hline WE4P5 & 34 & \multirow{2}{*}{3.1} & $2060 \pm 133 \mathrm{~N}$ & $414 \mathrm{~N}$ \\
\cline { 1 - 3 } WE4P6 & 34 & & $1716 \pm 120 \mathrm{~N}$ & $418 \mathrm{~N}$ \\
\hline
\end{tabular}

Notes: LI is Lifting Index, CF is L5/S1 compression force, SF is L5/S1 shear force, body dimension (162.8 cm, $57.4 \mathrm{~kg}) . \quad$ : Lower than AL, — : Higher than AL.

Table 3. The L5/S1 compression and shear forces based on the proposed maximum load for WE1, WE3, and WE4

\begin{tabular}{ccccc}
\hline Posture* $^{*}$ & Max-load (kg) & LI & CF (N) & SF (N) \\
\hline WE1P1 & 3.5 & 0.99 & $1107 \pm 65$ & 255 \\
WE3P2 & 10.5 & 1.07 & $2,265 \pm 165$ & 360 \\
WE3P3 & 10.5 & 1.07 & $1,500 \pm 99$ & 261 \\
WE3P4 & 10.5 & 1.07 & $1,091 \pm 45$ & 454 \\
WE4P5 & 10.5 & 0.97 & $1,242 \pm 76$ & 274 \\
WE4P6 & 10.5 & 0.97 & $933 \pm 56$ & 258 \\
\hline
\end{tabular}

Notes: LI is Lifting Index, CF is L5/S1 compression force, SF is L5/S1 shear force, body dimension $(162.8 \mathrm{~cm}, 57.4$ $\mathrm{kg})$.

\subsection{Discussion}

\subsubsection{Biomechanics analysis on the existed postures}

Lifting is considered the most common task associated with lower back injuries (Kuijer et al. 2011). Most of the lifting tasks in this oleoresin collecting activity are carried out under back lifting combined with asymmetric load. In most critical postures (Fig. 2), the load was placed on the body's right side. Among the six critical lifting-related working postures, the biomechanical analysis shows that lifting in WE3P2 and WE3P3 resulted in L5/S1 compression forces that exceeded the safety thresholds (Fig. 2, Table 2). We believe that these high L5/S1 spine loads are triggered not only by the load factor (resin buckets) but also by moderate-large forward trunk flexion that happened while finishing the work, as proven by the study of Arjmand et al. (2015). This high compression force will increase the risk of lower back injury (Chaffin and Andersson 
1991). Similar to compression force, the high shear force is associated with excessive biomechanical stress in L5/S1 and may increase the risk of injury (McGill et al. 1998). This study found that the high shear force on the L5/S1 disk exceeded the AL in WE3P2 and WE3P4 (Fig. 2, Table 2).

The standing balance analysis shows that unacceptable and critical standing balance was detected in WE3P2, WE4P5, and WE4P6. Even though the human central nervous system can continuously correct the standing balance by making "adjustments" for a better standing balance, an extensive adjustment may cause muscular imbalance (Nagymáté et al. 2018). Furthermore, this imbalance may trigger fatigue (Chen 2000), lowering the muscles' endurance to perform physical activity.

The load factor during WE1 progresses as the collected oleoresin' weight on the lugging bucket increases gradually. The time study analysis shows that the lugging bucket's total lifting duration, which got heavier (up to $34 \mathrm{~kg}$ maximum), was 97 minutes per working day with five lifts (and lowering)/minute. In addition, the same attention should be addressed to all selected postures in WE3 and WE4. In all these lifting-related postures, the psychophysical analysis reveals that the maximum load was excessive, approximately 3.1-9.7 times heavier than the calculated RWL (Table 2). Similar to muscular imbalance, this progressive load may trigger progressive fatigue, known to increase LBP (Banks and Aghazadeh 2009; Kuijer et al. 2011; Hasegawa et al. 2018).

This study also proves that lifting frequency is a factor that contributes to exacerbating pressure at L5/S1. WE1 with a higher lifting frequency will potentially lead to a more severe lower back injury than lifting work in WE3 and WE4 (Banks and Aghazadeh 2009; Hasegawa et al. 2018). Therefore, the load on WE1 must be much lighter than the load on WE3 and WE4. In their study, Ferguson et al. (2003) stated that when a load is combined with repetition motion, its impact on the L5/S1 compression force will be more damaging.

Overall, these findings indicate that the existing lifting-related working postures in manual oleoresin collecting work may risk the worker's occupational health due to the constraint barrier's load. A postural study using Rapid Entire Body Assessment and Rapid Upper Limb Assessment that was carried out on similar working postures showed similar results (Yovi and Fauzi 2021). They revealed that bending or half bending while collecting work might trigger MSDs. Therefore, ergonomic interventions are needed to reduce the level of risk. The proposed improvement should be uncomplicated to be applied in the implementation stage because most workers are highly dependent on this work to make a living and have limited financial ability to afford any additional costs (Yovi and Yamada 2019).

\subsubsection{Biomechanics analysis on the proposed interventions}

Both postural and psychophysical analyses indicate the existence of excessive lifting. Therefore, an alternative working technique is necessary. This study verifies that working posture and load are the factors that influence the L5/S1 compression and shear force, which is in line with Han et al. (2013). Therefore, lifting techniques need to be improved by considering two factors contributing to MSDs: working postures and loads (Gallis 2006).

In this study, we focused on the discussion about load-related interventions that are very applicable. The proposed alternative work technique originated from the load-related scenario, i.e., reducing the maximum load according to the RWL. This load reduction strategy does not demand 
drastic changes in working postures. In the proposed technique, the workers will use a $3.5 \mathrm{~kg}$ capacity bucket and repeatedly pour the oleoresin into a bigger bucket until it is full. After three times repetition, the workers then transferred $10.5 \mathrm{~kg}$ of oleoresin to a bigger drum at the transitory storage point. In the current collecting technique, the workers carry a big bucket until it is filled with a 34-kg load (full bucket). After that, they hauled the bucket into the transitory storage point and then poured the $34 \mathrm{~kg}$ of oleoresin into a bigger drum (Fig. 3). The proposed alternative process demands a longer working time, especially for repeated walking. However, this weightreducing strategy has shown a significant compression and shear force reduction, directly associated with the lower MSDs risk (Table 3). This scenario will effectively reduce LBP risk, as Waters et al. (1999) proved that $1<\mathrm{LI}<3$ has a consistently positive relationship with LBP.

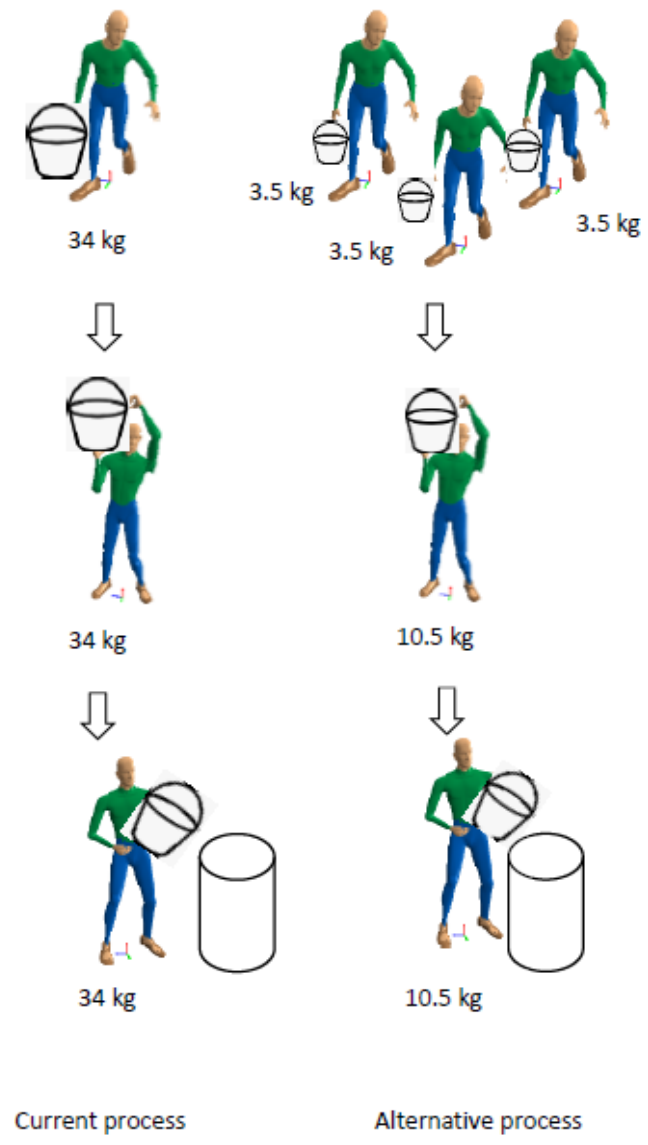

Fig. 3. A proposed oleoresin collecting work with the lighter load as suggested by the calculated RWL.

\section{Conclusions}

The pine oleoresin collecting activity is dominated by MMH activities, especially lifting tasks, which expose the workers to a high risk of occupational health disorders. The biomechanical analysis reveals that the observed current oleoresin collecting techniques (involving a $34 \mathrm{~kg}$ fullload oleoresin bucket) result in L5/S1 compression and shear forces over the permissible limits (AL). In the current process, the LI values at all the working elements were far higher than 1, indicating that this activity might cause physical stress in the long run. The smaller oleoresin buckets (regardless of the longer time required for walking), intended to ensure that the load lifted does not exceed the RWL, will significantly reduce the L5/S1 compression and shear forces. 


\section{References}

Arjmand, N., Amini, M., Shirazi-Adl, A., and Parnianpour, M. 2015. Revised NIOSH Lifting Equation May Generate Spine Loads Exceeding Recommended Limits. International Journal of Industrial Ergonomics 47: 1-8. DOI: 10.1016/j.ergon.2014.09.010

Banks, A. D., and Aghazadeh, F. 2009. Progressive Fatigue Effect on Manual Lifting Factors. Human Factor and Ergonomics in Manufacturing \& Service Industries 19(5): 361-377. DOI: $10.1002 / \mathrm{hfm} .20170$

BPS. 2017. Statistik Perusahaan Pembudidaya Tanaman Kehutanan 2016. Badan Pusat Statistik (BPS), Jakarta, Indonesia.

Chaffin, D. B., and Andersson, G. 1991. Occupational Biomechanics. Second Edition. John Wiley \& Sons, Inc., New York, USA.

Chaffin, D. B., Andersson, G. B. J., and Martin, B. J. 2006. Occupational Biomechanics, 4th Edition. John Wiley \& Sons, Inc., New Jersey.

Chen, Y. 2000. Changes in Lifting Dynamics after Localized Arm Fatigue. International Journal of Industrial Ergonomics 25: 611-619. DOI: 10.1016/S0169-8141(99)00048-7

Cunningham, A. 2012. Pine Resin Tapping Techniques Used Around The World. In: Arthur G. Fett-Neto, Kelly CS Rodrigues-Corrêa, editors. Pine Resin: Biology, Chemistry and Applications. Research Signpost, Kerala.

Dempsey, P. G., McGorry, R. W., and Maynard, W. S. 2005. A Survey of Tools and Methods Used by Certified Professional Ergonomists. Applied Ergonomics 36(4): 489-503. DOI: 10.1016/j.apergo.2005.01.007

Dutmer, A. L., Preuper, H. R. S., Soer, R., Brouwer, S., Bültmann, U., Dijkstra, P. U., Coppes, M. H., Stegeman, P., Buskens, E., van Asselt, A. D. I., Wolff, A. P., and Reneman, M. F. 2019. Personal and Societal Impact of Low Back Pain. SPINE 44(24): E1443-1451. DOI: 10.1097/BRS.0000000000003174

Ferguson, S. A., Allread, W. G., Rose, J., and Marras, W. S. 2003. Shoulder Muscle Fatigue During Repetitive Tasks as Measured by Electromyography and Near-Infrared Spectroscopy. Human Factors 55(6): 1077-1087. DOI: 10.1177/0018720813482328

Fujii, T., and Matsudaira, K. 2013. Prevalence of Low Back Pain and Factors Associated with Chronic Disabling Back Pain in Japan. Europian Spine Journal 22: 432-438. DOI: $10.1007 / \mathrm{s} 00586-012-2439-0$

Gallis, C. 2006. Work-Related Prevalence of Musculoskeletal Symptoms among Greek Forest Workers. International Journal of Industrial Ergonomics 36(8): 731-736. DOI: 10.1016/j.ergon.2006.05.007

Han, K. S., Rohlmann, A., Zander, T., and Taylor, W. R. 2013. Lumbar Spinal Loads Vary with Body Height and Weight. Medical Engineering and Physics 35: 969-977. DOI: 10.1016/j.medengphy.2012.09.009

Hasegawa, T., Katsuhira, J., Oka, H., Fujii, H., and Matsudaira, K. 2018. Association of Low Back Load with Low Back Pain during Static Standing. PLoS One 13(12): e0208877. DOI: 10.1371/journal.pone.0208877

Husky, M. M., Farin, F. F., Compagnone, P., Fermanian, C., and Kovess-Masfety, V. 2018. Chronic Back Pain and Its Association with Quality of Life in A Large French Population Survey. Health Qual Life Outcomes 16: 195. DOI: 10.1186/s12955-018-1018-4

Jourgholami, M., Majnounian, B., and Zargham, N. 2013. Performance, Capability and Costs of Motor-Manual Tree Feeling in Hyrcanian Hardwood Forest. Croatian Journal of Forest Engineering 34(2): 283-293.

Kee, D., and Karwowski, W. 2007. A Comparison of Three Observational Techniques for Assessing Postural Loads in Industry. International Journal of Occupational Safety and Ergonomics 13(1): 3-14. DOI: 10.1080/10803548.2007.11076704

Knudson, D. 2007. Fundamentals of Biomechanics, 2nd Edition. Springer, NY.

Kuijer, P. P., Frings-Dresen, M. H., and Gouttebarge, V. 2011. Low Back Pain: We Cannot Afford Ignoring Work. The Spine Journal 11(2): 164-168. DOI: 10.1016/j.spinee.2010.10.016 
Kumar, S. 2001. Theories of Musculoskeletal Injury Causation. Ergonomics 44(1): 17-47. DOI: $10.1080 / 00140130120716$

Lambeek, L. C., van Tulder, M. W., Swinkels, I. C., Koppes, L. L. J., Anema, J. R., and van Mechelen, W. 2011. The Trend in Total Cost of Back Pain in The Netherlands in The Period 2002 to 2007. Spine (Phila Pa 1976) 36: 1050-1058. DOI: 10.1097/BRS.0b013e3181e70488

McGill, S. M., Norman, R. W., Tingling, V. R., Wells, R. P., and Neumann, P. 1998. Shear Happens! Suggested Guidelines for Ergonomists to Reduce The Risk of Low Back Injury from Shear Loading. In: Proceeding of The 30th Annual Conference of The Human Factors Association of Canada (HFAC): 157-161.

Nagymáté, G., Takács, M., and Kiss, R. M. 2018. Does Bad Posture Affect The Standing Balance. Cogent Medicine 5: 1. DOI: 10.1080/2331205X.2018.1503778

Nelson, G. S., and Wickes, E. J. T. 1995. Manual Lifting: The Revised NIOSH Lifting Equation for Evaluating Acceptable Weights for Manual Lifting. $<$ http://www.hazardcontrol.com/factsheets/pdfs/NIOSH-1994.pdf $>$ (April 8, 21).

NIOSH. 1981. Work Practices Guide for Manual Lifting. Technical Report Number 81-122, US Department of Health and Human Services, Cincinnati, Ohio. $<$ http://www.hazardcontrol.com/factsheets/pdfs/NIOSH-1994.pdf $>$ (Nov. 30, 2020).

NIOSH. 1994. Applications Manual for The Revised NIOSH Lifting Equation. $<$ http://www.cdc.gov/niosh> (Nov. 30, 2020).

Openshaw, S., and Taylor, E. 2006. Ergonomics and Design A Reference Guide. Allsteel Inc., Iowa, United States.

Sakka, S., Chablat, D., Ma, R., and Bennis, F. 2015. Predictive Model of the Human Muscle Fatigue: Application to Repetitive Push-Pull Tasks with Light External Load. International Journal of Human Factors Modelling and Simulation 5(1): 81-97. DOI: 10.1504/ijhfms.2015.068124

Vos, T., Flaxman, A. D., Naghavi, M., Lozano, R., Michaud, C., Ezzati, M., et al. 2013. Years Lived with Disability (YLDS) for 1160 Sequelae of 289 Diseases and Injuries 1990-2010: A Systematic Analysis for The Global Burden of Disease Study 2010. Lancet 380(9859): 2163-2196. DOI: 10.1016/s0140-6736(12)61729-2

Waters, T. R., Putz-Anderson, V., Garg, A., and Fine, L. J. 1993. Revised NIOSH Equation for the Design and Evaluation of Manual Lifting Tasks. Ergonomics 36(7): 749-776. DOI: 10.1080/00140139308967940

Waters, T. R., Baron, S. L., Piacitelli, L. A., Anderson, V. P., Skov, T., Haring-Sweeney, M., Wall, D. K., and Fine, L. J. 1999. Evaluation of The Revised NIOSH Lifting Equation. A CrossSectional Epidemiologic Study. Comparative Study 24(4): 386-94. DOI: 10.1097/00007632199902150-00019.

Yovi, E. Y., Takimoto, Y., Ichihara, K., and Matsubara, C. 2005. Factors Affecting Workload and Work Efficiency in Pine Resin Harvesting Operations in Java's Plantation Forests. Journal of The Japan Forest Engineering Society 20(3): 141-150. DOI: 10.18945/jjfes.KJ00007485372

Yovi, E. Y., and Fauzi, A. 2021. Ergonomics Risk Assessment in Pine Resin Harvesting: A Static Postural Analysis. Jurnal Sylva Lestari 9(1): 104-120. DOI: 10.23960/js119104-120

Yovi, E. Y., and Yamada, Y. 2019. Addressing Occupational Ergonomics Issues in Indonesian Forestry: Laborers, Operators or Equivalent Workers. Croatian Journal of Forest Engineering 40(2): 351-363. DOI: 10.5552/crojfe.2019.558 